\title{
Seasonal Variability of the Buoyancy Flux along the Northern Coast of the Gulf of Guinea
}

\author{
Elisee Toualy1,2*, Angora Aman', Marcel Silué ${ }^{1}$ \\ ${ }^{1}$ Climate Tropical Team, LASMES, Université Felix Houphouët Boigny, Abidjan, Côte d'Ivoire \\ ${ }^{2}$ School of Science, Engineering, Technology and Mathematics (STEM), International University of Grand Bassam, Côte d'Ivoire \\ Email: *elisee.toualy@gmail.com
}

How to cite this paper: Toualy, E., Aman, A. and Silué, M. (2021) Seasonal Variability of the Buoyancy Flux along the Northern Coast of the Gulf of Guinea. Atmospheric and Climate Sciences, 11, 363-372. https://doi.org/10.4236/acs.2021.112021

Received: January 28, 2021

Accepted: April 27, 2021

Published: April 30, 2021

Copyright $\odot 2021$ by author(s) and Scientific Research Publishing Inc. This work is licensed under the Creative Commons Attribution International License (CC BY 4.0).

http://creativecommons.org/licenses/by/4.0/

(c) (i) Open Access

\begin{abstract}
The buoyancy flux Bo at the air/sea interface is very useful to understand the variability of the stratification of the mixed layer, the oceanic mixing, the phytoplankton dynamics and then the coastal upwelling. The atmospheric reanalysis ERA5 and the oceanic reanalysis ORAP5 data have been used in this study to describe the sea surface Bo and, its influence on the variability of the mixing in the mixed layer and consequently on the coastal upwelling along the northern coast of the Gulf of Guinea. The Bo is negative along the coast and, is characterized by a seasonal variability dominated by the thermal buoyancy flux. This study has also shown that the mixing layer is very shallow along the coast and deeper offshore. The negative value of the Bo increases the stratification of the mixed layer and reduces the mixing. This could explain why the mixed layer is shallow in this region. This work suggests that an increasing trend of the global warming could have dramatic impact in this area by increasing the stratification in the mixed layer and would contribute to reducing the coastal upwelling intensity.
\end{abstract}

\section{Keywords}

Gulf of Guinea, Surface Buoyancy Flux, Coastal Upwelling, Thermal Buoyancy Flux, Haline Buoyancy Flux, Mixing Layer

\section{Introduction}

The Gulf of Guinea (GG) is located in the Atlantic Ocean from $20^{\circ} \mathrm{W}$ to the western coast of Africa at cap Lopez $\left(8^{\circ} 43^{\prime} \mathrm{E}\right)$ and from $10^{\circ} \mathrm{S}$ to the African coast around $5^{\circ} \mathrm{N}$ (Figure 1). This region is characterized by an Atlantic cold tongue along the equator [2] [3] and a seasonal upwelling is observed from December to March and from July to August along its northern coast [4] [5] [6] [7]. The 


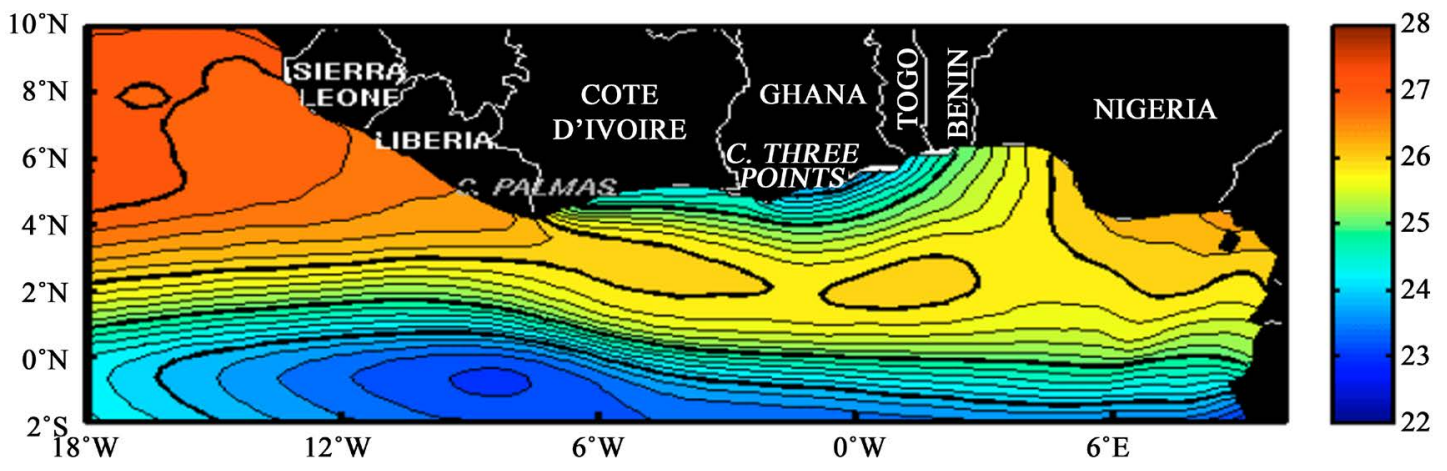

Figure 1. Sea surface temperature in the Gulf of Guinea (courtesy from [1]). The two regions of weak temperature represent respectively the Atlantic cold tongue along the equator and the coastal upwelling off Cote d'Ivoire and Ghana.

coastal area and particularly, the region of Cote d'Ivoire and Ghana retaining the attention of this work are more complex because of being the principal region of the occurrence of the coastal upwelling and also the area of freshwaters intrusion from the tropical rainfall, the rivers and the lagoons [4] [8]. This coastal upwelling is very important for the climate of the bordering countries of the GG, the marine ecosystem of this region, the phytoplankton dynamic and, the fishery [4] [5] [6] [7] [9] [10] [11]. Unfortunately the physical mechanisms of this upwelling are still discussed [5] [12] [13]. Many mechanisms have been put forward to explain this upwelling, among them, the cooling by the mixing due to current shear in the mixed layer seems to be a dominant process [13]. Few studies on the mixed layer depth have shown that this depth is very shallow during the whole year [14]. But no other study has tried to understand why the mixed layer is shallow, and especially the contribution of the Buoyancy flux in the mixing of the mixed layer in this area. This is one of the main reasons of this work.

The Bo is important when analyzing the mechanisms of the ocean-atmosphere interactions [15]. The Bo plays an important role in water mass transformation, mixing, stratification of water levels [15] [16], gas transfer in ocean [17], vertical nutrient transport [11] and, then on the upwelling. This important parameter depends on the heat and the freshwater fluxes [15]. One of the challenges involving the Bo study for a particular region is relative to the determination of the quantity that allows capturing of the relative contribution of the two components (thermal and haline) of the buoyancy flux in one single quantity [15] [18] [19] [20]. The net Bo is dominated over a larger part of the ocean area by the thermal component $\mathrm{Bq}$ [21]. But it is the concomitant action of both that determine the impact of atmospheric and oceanic changes on the ocean ventilation [15] [22] [23]. Unfortunately, the previous studies on ocean-atmosphere interaction did not focus on the Bo in the GG. So which of the thermal or the freshwater buoyancy flux dominates the buoyancy flux in the GG? Thus, the present study focuses on the: 1) net Bo and, 2) determination of the dominant component of the Bo in the GG. An application of the Bo to the determination of the mixing layer has been further evaluated in this region. Besides, the significance 
of these results for the dynamic of the mixed layer and then for the coastal upwelling of this region has been discussed.

In this work, we have first combined the oceanic and atmospheric reanalyses in order to compute the Bo and from the sign of the Bo, we have indirectly estimated the contribution of the Bo to the oceanic mixing, the mixing layer and the coastal upwelling of this region. The outline of this work is presented as follows. Section 2 describes the data and gives an overview of the methods used to estimate the buoyancy flux and the mixing layer. The results are presented in Section 3. The results and the significance of this work have been discussed and concluded respectively in Sections 4 and 5.

\section{Data and Methods}

\subsection{Data}

This study combines the atmospheric and the oceanic reanalyses data provided respectively by the European atmospheric reanalysis ERA5 and the new eddy-permitting ocean reanalysis called Ocean Reanalysis Pilot (ORAP5). These reanalyses have been both completed at the European Centre for Medium-Range Weather Forecasts (ECMWF) and they span respectively over the period 1979-2012 for the ORAP5 [24] and 1979-onwards for the ERA5 [25]. The ECMWF produces the ERA5 and the ORAP5 reanalyses within the Copernicus Climate Change Service. The ERA5 provides global hourly estimates of the atmospheric variables at a spatial resolution of $31 \mathrm{~km}$ and 137 vertical levels from the surface to $0.01 \mathrm{hPa}$. The ERA5 has been improved from its predecessors with some improvements in the models, the dynamic cores and the data assimilation [25]. The atmospheric data used are the daily precipitation, the evaporation and the wind at the sea surface. The unit of the precipitation and the evaporation is $\mathrm{m} /$ day. The oceanic ORAP5 reanalysis is produced using the NEMO ocean model [26] at a spatial resolution of $25 \mathrm{Km}$ between two consecutive grid points and 75 levels in the vertical [25]. For this study, the oceanic data used are the net heat flux $Q_{0}$ at the sea surface and, the sea surface salinity (S) and temperature (SST). $\mathrm{Q}_{0}, \mathrm{~S}$ and SST are monthly data. The units of $\mathrm{Q}_{0}$ and $\mathrm{S}$ are respectively $\mathrm{W} \cdot \mathrm{m}^{-2}$ and $\mathrm{psu}$. The data used for this study cover the period 1995-2005.

\subsection{Method}

The surface buoyancy flux depends on the net heat flux or the thermal condition (Bq) and the variability of the freshwater amount or the haline component (Bp). The Bo is calculated from the atmospheric and the oceanic parameters at the sea surface [15] [16] [18] [19]. The buoyancy flux is calculated as follows according to [18]:

$$
B o=B q+B p=-g \times \alpha \times \frac{Q_{0}}{\rho C_{p}}+g \times \beta \times(E-P) S
$$

The gravity is $g=10 \mathrm{~m} \cdot \mathrm{s}^{-2} ; Q_{0}$ the net heat flux at the sea surface, $\rho$ the ocean density computation is based on the equation of sea water, while constant values 
are $\alpha$ the effective thermal expansion coefficient and $\beta$ the effective haline contraction coefficient. The evaporation $(E)$ and precipitation $(P)$ data are divided by $86,400 \mathrm{~s}$ to have the $\mathrm{m} / \mathrm{s}$ unit. Finally, the unit of the Bo is $\mathrm{m}^{2} \cdot \mathrm{s}^{-3}$.

A negative (i.e., downward) buoyancy flux, due to either the surface warming or the precipitation, tends to make the ocean surface more buoyant and subsequently stable. Conversely, a positive Bo, due to either the surface cooling or the evaporation, tends to make the ocean surface less buoyant. As the water column loses buoyancy, it can become unstable with heavy water lying over lighter water [18].

One important application of the Bo is the determination of the mixing layer, the depth at which the turbulence generated by the wind is balanced by the Bo.

The wind friction is $u^{*}=\sqrt{\frac{\tau}{\rho}}$ with $\tau$ corresponding to the wind stress at the surface and $\rho_{\mathrm{o}}$ the density of surface water. The wind data are obtained from atmospheric reanalysis ERA5. The wind stress is calculated from the wind at $10 \mathrm{~m}$ above the sea surface using the drag coefficient determined by the relationship of [27]:

$$
\tau=C_{D} \times \rho_{\text {air }} \times u^{2}
$$

The mixing layer depth or the Monin-Obukhov length L [28] is:

$$
L=\frac{-u^{* 3}}{\kappa B o}
$$

with $k=0.41$ the Von Karman's constant.

\section{Results}

\subsection{Temporal Variability of the Buoyancy Flux and Its Components}

Figure 2 shows the climatology of the $\mathrm{Bo}, \mathrm{Bq}, \mathrm{Bp}$ and the ratio of the thermal over the haline buoyancy fluxes along the northern coast of the GG. The Bo is negative in the GG. Its weakest values are around $-4 \times 10^{-8} \mathrm{~m}^{2} \cdot \mathrm{s}^{-3}$ and they are observed over the region of the coastal upwelling of the GG. These values increase offshore tending to positive values. The highest values around $-0.5 \times 10^{-8}$ $\mathrm{m}^{2} \cdot \mathrm{s}^{-3}$ are observed over the warm pool between $2^{\circ} \mathrm{N}$ and $4^{\circ} \mathrm{N}$.

The thermal buoyancy flux Bq also displays similar patterns as the net Bo with a core of negative values ranging between $-3 \times 10^{-8} \mathrm{~m}^{2} \cdot \mathrm{s}^{-3}$ and $-2 \times 10^{-8} \mathrm{~m}^{2} \cdot \mathrm{s}^{-3}$ in the coastal upwelling region. These values increase southward and reaching -0.1 $\times 10^{-8} \mathrm{~m}^{2} \cdot \mathrm{s}^{-3}$ around $2^{\circ} \mathrm{N}$. The positive values are observed in the West of $9^{\circ} \mathrm{W}$ over the warm pool.

The haline buoyancy flux $\mathrm{Bp}$ is negative in the GG. The highest values of $\mathrm{Bp}$ are recorded along the northern coast while the minimum values are in the south and particularly over the warm pool. The values along the coast are higher than $-1 \times 10^{-8} \mathrm{~m}^{2} \cdot \mathrm{s}^{-3}$ and they decrease to values more and more negative offshore. The ratio of the thermal over the haline buoyancy flux is maximum along 

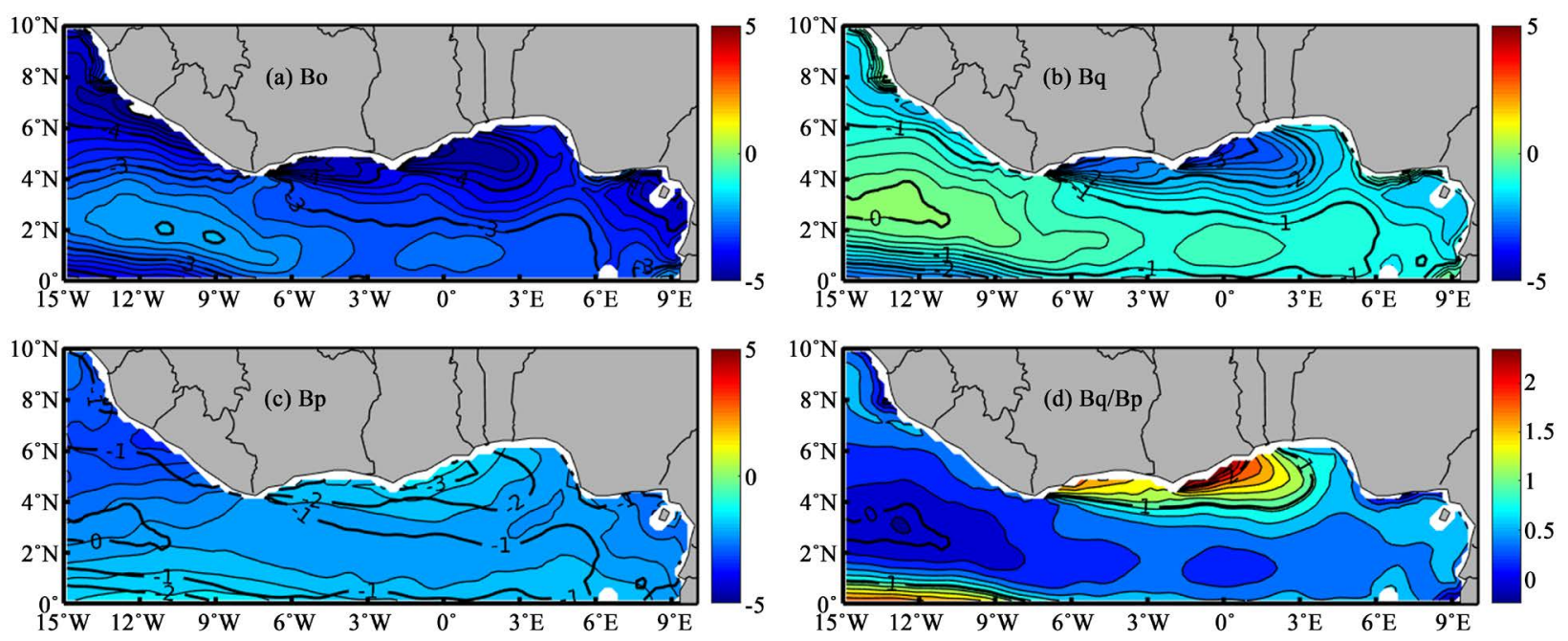

Figure 2. Spatial distribution of the climatology of the net buoyancy flux (panel (a)), the thermal buoyancy flux (panel (b)), the haline buoyancy flux (panel (c)) and, the ratio of the thermal over haline buoyancy flux (panel (d)) off Cote d'Ivoire and Ghana. The data have been averaged over the periods 1995-2005 to build the climatology. Intervals between contours are 0.2 $\times 10^{-8} \mathrm{~m}^{2} \cdot \mathrm{s}^{-3}$ for the different buoyancy fluxes. The core of negative Bo is observed off Cote d'Ivoire and Ghana in the region of the coastal upwelling.

the northern coast of GG and minimum in the south. The ratio is greater than 3 along the coast and decreases southward reaching values less than 1 . The Bt flux is more important at the coast and contributes more to the net buoyancy flux there. While south of $3^{\circ} \mathrm{N}$, the Bp becomes more important than the Bq. The ratio of the thermal over the haline buoyancy fluxes shows that the haline buoyancy flux represents one fourth of the thermal buoyancy flux along the coast. In the South of $3^{\circ} \mathrm{N}$, the $\mathrm{Bp}$ is greater than the $\mathrm{Bq}$ and the ratio shows that $\mathrm{Bp}$ corresponds to one half of the Bq.

Figure 3 shows the seasonal variability of the Bo and its components along the northern coast of the GG. The Bo and the Bq are characterized by a seasonal variability with maximum values in June and two minima in March and October. The $\mathrm{Bp}$ is negative all the year and it has two maxima respectively in January and August-September. The Bo decreases from January to reach a minimum and negative value of $-4 \times 10^{-8} \mathrm{~m}^{2} \cdot \mathrm{s}^{-3}$ in March before increasing until June when it reaches an absolute maximum value of $2 \times 10^{-8} \mathrm{~m}^{2} \cdot \mathrm{s}^{-3}$. It decreases from its maximum value in June to reach minimum values in July, August, September and October. The absolute minimum value around $-5 \times 10^{-8} \mathrm{~m}^{2} \cdot \mathrm{s}^{-3}$ is observed in October. It increases from October to a maximum value in December-January. The thermal buoyancy flux governs almost $70 \%$ of the variability of the net buoyancy flux with the peak of highest values around $1 \times 10^{-8} \mathrm{~m}^{2} \cdot \mathrm{s}^{-3}$ when the net buoyancy flux reaches $2 \times 10^{-8} \mathrm{~m}^{2} \cdot \mathrm{s}^{-3}$ and the haline buoyancy flux is around $-1 \times 10^{-8} \mathrm{~m}^{2} \cdot \mathrm{s}^{-3}$.

\subsection{Variability of the Mixing Layer}

Figure 4 shows the climatology of the mixing layer along the northern coast of the GG. The mixing layer is very shallow along the coastline north of $3^{\circ} \mathrm{N}$ and 


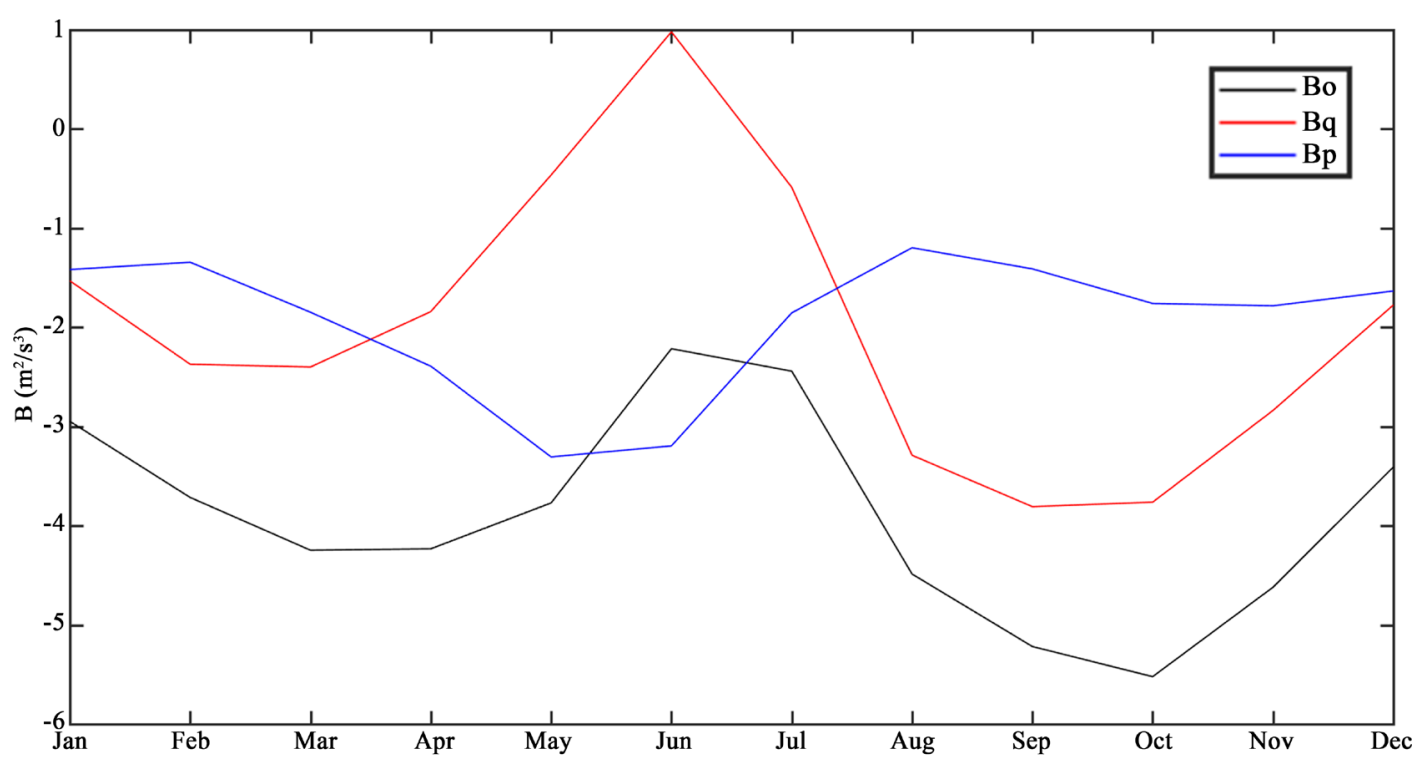

Figure 3. Seasonal variability of the buoyancy, the thermal and the haline fluxes along the northern coast of the Gulf of Guinea. The data have been averaged in the coastal domain $\left[7^{\circ} \mathrm{W}-3^{\circ} \mathrm{E} \times 3^{\circ} \mathrm{N}-5^{\circ} \mathrm{N}\right]$ for the respective months of the calendar to get the monthly climatology.

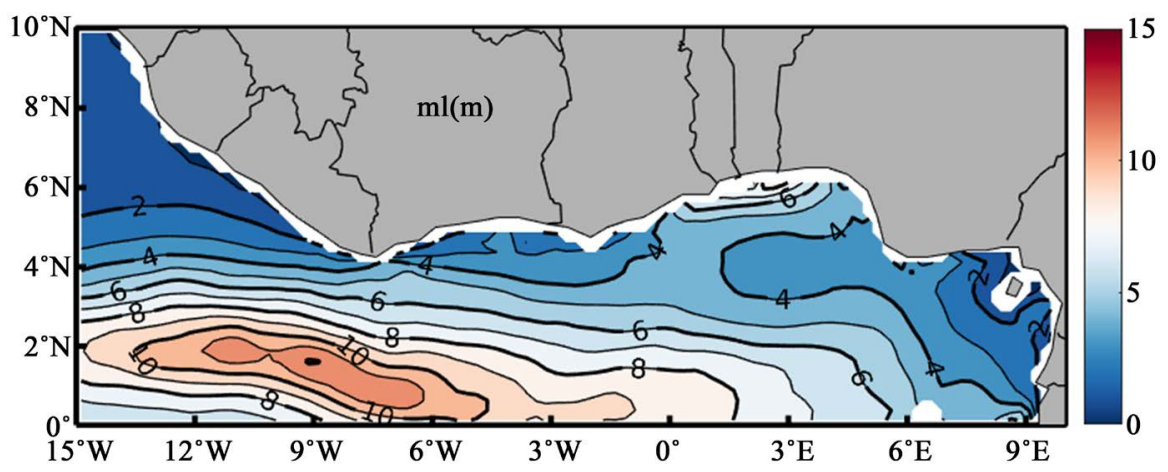

Figure 4. Spatial distribution of the climatology of the mixing layer along the northern coast of the Gulf of Guinea. The monthly data have been averaged over the period 1995-2005 to build the monthly climatology. Intervals between contours are $2 \mathrm{~m}$.

is deeper south of this latitude. It stays almost constant along the coastline from the Cap Palmas to Ghana. It increases southward to bigger values. The values are less than $5 \mathrm{~m}$ North of $3^{\circ} \mathrm{N}$ while it increases quickly South of this position reaching $30 \mathrm{~m}$ around $2^{\circ} \mathrm{N}$ over the warm pool. The weakest values of the mixing layer are recorded over the region of the weakest Bo while the strongest values of the mixing layer coincide with the region of the highest Bo in the GG.

\section{Discussion}

This study uses the net heat flux at the sea surface, the evaporation and the rainfall data from the oceanic (ORAP5) and the atmospheric (ERA5) reanalyses to describe the net buoyancy flux Bo along the northern coast of the GG. The analysis of the results showed that the Bo is negative and the mixing layer is shallow along the coast. The Bo increases the stratification which reduces the mixing and 
consequently the mixing layer [15] [18]. This could explain the shallow mixed layer observed along the northern coast of the GG [14]. The peak of the negative Bo is noticed since the period of the major upwelling in July-August-September till October [1] [4] [5] [6] [7]. This shows that the Bo will reduce the intensity of the mixing during the upwelling season and consequently works again the mechanism of cooling by mixing during this upwelling [13]. The role of the buoyancy flux on the mixed layer along the northern coast of the GG would have a negative impact on the phytoplankton dynamic and the fishery of this area [11]. The negative buoyancy is due to the heat flux that warms strongly the mixed layer during the upwelling season. The increasing trend of the global warming will increase the role of the buoyancy flux and consequently the stratification of the mixed layer along the northern coast of the GG.

The thermal buoyancy flux Bq dominates the Bo off the coast but offshore, the freshwater buoyancy flux $\mathrm{Bp}$ is very important. The ratio $\mathrm{Bq} / \mathrm{Bp}$ is in favor of the $\mathrm{Bq}$, but this method of analyzing the flux ratio [16] cannot be fully used in the GG because the two components of the Bo are both negative over large domain of the GG excepted in the west of $9^{\circ} \mathrm{W}$ over the warm pool where the Bp is positive. Also this ratio method presents some disadvantages in the GG because, it gives sometimes nil values [15]. Most of the studies on the surface ocean buoyancy forcing focus on the thermal component because it controls the seasonal variability of the Bo [21]. In the GG, the freshwater buoyancy flux represents one fourth of $\mathrm{Bq}$ and then could not be neglected. Besides, [22] and [23] sustain that the haline buoyancy flux is crucial for long-term variability of the atmosphere/ocean system. In the Indian Ocean, [20] didn't include evaporation in the freshwater component of the Bo. In the GG, the evaporation is very important for the estimation of $\mathrm{Bp}$ and for the dynamic of the coastal upwelling [7]. [7] attributed the SST cooling during the major coastal upwelling along the northern coast of GG to the evaporation showing then the role of the mixing due to positive buoyancy flux and therefore the crucial role of Bp among the physical mechanism of this coastal upwelling. Unfortunately, our study shows that buoyancy flux inhibits the upwelling.

\section{Conclusion}

This study describes the buoyancy flux and its components in the GG and particularly along the northern coast of the GG using the oceanic and the atmospheric reanalysis data. The Bo is negative all the year excepted during June. It is characterized by a seasonal variability modulated by the seasonal variability of the rainfall and the net heat flux in the GG. In this region, the thermal and haline buoyancy fluxes play an important role and both should be used to determine precisely the Bo. The mixing layer in this region is shallower close to the northern coast of the GG because of the negative Bo; while offshore toward the warm pool it becomes much deeper because of the maximum values of the Bo tending to positive values. In this region, the Bo induces a stratification of the 
mixed layer and then reduces the mixing which is very important to sustain the cooling during the upwelling season. The Bo doesn't enhance the vertical mixing and the phytoplankton bloom. With the increasing trend of the global warming, the Bo will contribute to reducing the coastal upwelling intensity along the northern GG.

\section{Acknowledgements}

The Atmospheric and the Oceanic reanalyses data are freely available through the Copernicus website. Authors thank the anonymous reviewers for their helpful comments.

\section{Funding}

This research did not receive any specific grant from funding agencies in the public, commercial, or not-for-profit sectors.

\section{Conflicts of Interest}

The authors declare no conflicts of interest regarding the publication of this paper.

\section{References}

[1] Toualy, E., Stanojevic, G., Kouadio, K.Y. and Aman, A. (2012) Multi-Decadal Variability of Sea Surface Temperature in the Northern Coast of Gulf of Guinea. Asian Journal of Applied Sciences, 5, 552-562. https://doi.org/10.3923/ajaps.2012.552.562

[2] Caniaux, G., Giordani, H., Redelsperger, J-L., Guichard, F., Key, E. and Wade, M. (2011) Coupling between the Atlantic Cold Tongue and the West African Monsoon in Boreal Spring and Summer. Journal of Geophysical Research-Oceans, 116, Article ID: C040037. https://doi.org/10.1029/2010JC006570

[3] Weingartner, T.J. and Weisberg, R.B. (1991) On the Annual Cycle of Equatorial Upwelling in the Central Atlantic Ocean. Journal of Physical Oceanography, 21, 68-82. https://doi.org/10.1175/1520-0485(1991)021<0068:OTACOE >2.0.CO;2

[4] Bakun, A. (1978) Guinea Current Upwelling. Nature, 271, 147-150. https://doi.org/10.1038/271147a0

[5] Djakouré, S., Penven, P., Bourlès, B., Koné, V. and Veitch, J. (2017) Respective Role of the Guinea Current and Local Winds on the Coastal Upwelling in the Northern Gulf of Guinea. Journal of Physical Oceanography, 47, 1367-1387. https://doi.org/10.1175/JPO-D-16-0126.1.

[6] Hardman-Mountford, N.J. and McGlade, J.M. (2003) Seasonal and Interannual Variability of Oceanographic Processes in the Gulf of Guinea: An Investigation Using AVHRR Sea Surface Temperature Data. International Journal of Remote Sensing, 24, 3247-3268. https://doi.org/10.1080/0143116021000021297

[7] Pople, W. and Mensah, M. (1971) Evaporation as the Upwelling Mechanism in Ghanaian Coastal Waters. Nature Physical Science, 234, 18-20. https://doi.org/10.1038/physci234018a0

[8] Scherena, P.A.G.M., Kroezeb, C., Janssena, F.J.J.G., Hordijkc, L. and Ptasinskia, K.J. (2004) Integrated Water Pollution Assessment of the Ebrié Lagoon, Ivory Coast, West Africa. Journal of Marine Systems, 44, 1-17. 
https://doi.org/10.1016/j.jmarsys.2003.08.002

[9] Ali, K.E., Kouadio, K.E., Zahiri, E.P., Aman, A., Assamoi, A.P. and Bourlès, B. (2011) Influence of the Gulf of Guinea Coastal and Equatorial Upwellings on the Precipitation along Its Northern Coasts during the Boreal Summer Period. Asian Journal of Applied Sciences, 4, 271-285. https://doi.org/10.3923/ajaps.2011.271.285

[10] Aman, A., Toualy, E. and Yoroba, F. (2018) On the Causes of the Minor Dry Season over the Coastal Region of the Northern Gulf of Guinea. Atmospheric and Climate Science, 8, 121-133. https://doi.org/10.4236/acs.2018.82009

[11] Geng, B., Xiu, P., Shu, C., Zhang, W.-Z., Chai, F., Li, S. and Wang, D. (2019) Evaluating the Roles of Wind- and Buoyancy Flux-Induced Mixing on Phytoplankton Dynamics in the Northern and Central South China Sea. Journal of Geophysical Research: Oceans, 124, 680-702. https://doi.org/10.1029/2018JC014170

[12] Picaut, J. (1983) Propagation of the Seasonal Upwelling in the Eastern Equatorial Atlantic. Journal of Physical Oceanography, 13, 18-37. https://doi.org/10.1175/1520-0485(1983)013<0018:POTSUI >2.0.CO;2

[13] Jouanno, J., Marin, F., du Penhoat, Y., Molines, J.M. and Sheinbaum, J. (2011) The Seasonal Modes of Surface Cooling in the Gulf of Guinea. Journal of Physical Oceanography, 41, 1408-1416. https://doi.org/10.1175/JPO-D-11-031.1

[14] N'Guessan, B.K., Kouassi, A.M., Trokourey, A., Toualy, E., Kanga, D.K. and Brehmer, P. (2020) Eastern Tropical Atlantic Mixed Layer Depth: Assessment of Methods from in Situ Profiles in the Gulf of Guinea from Coastal to High Sea. Thalassas: An International Journal of Marine Sciences, 36, 201-212. https://doi.org/10.1007/s41208-019-00179-7

[15] Karstensen, J. and Lorbacher, K. (2011) A Practical Indicator for Surface Ocean Heat and Freshwater Buoyancy Fluxes and Its Application to the NCEP Reanalysis Data. Tellus A, 63, 338-347. https://doi.org/10.1111/j.1600-0870.2011.00510.x

[16] Zhang, H.M. and Talley, L.D. (1998) Heat and Buoyancy Budgets and Mixing Rates in the Upper Thermocline of the Indian and Global Oceans. Journal of Physical Oceanography, 28, 1961-1978. https://doi.org/10.1175/1520-0485(1998)028<1961:HABBAM >2.0.CO;2

[17] MacIntyre, S., Jonsson, A., Jansson, M., Aberg, J., Turney, D.E. and Miller, S.D. (2010) Buoyancy Flux, Turbulence, and the Gas Transfer Coefficient in a Stratified Lake. Geophysical Research Letters, 37, L24604. https://doi.org/10.1029/2010GL044164

[18] Cronin, M.F. and Sprintall, J. (2001) Wind and Buoyancy-Forced Upper Ocean. In: Steele, J.H., Ed., Elements of Physical Oceanography, Academic Press, Cambridge, 3217-3224. https://doi.org/10.1006/rwos.2001.0157

[19] Gill, A.E. (1982) Atmosphere-Ocean Dynamics. International Geophysics Series, Academic Press, New York.

[20] Anitha, G., Ravichandran, M. and Sayanna, R. (2008) Surface Buoyancy Flux in Bay of Bengal and Arabian Sea. Annales Geophysicae, 26, 395-400. https://doi.org/10.5194/angeo-26-395-2008

[21] Large, W.G. and George Nurser, A.J. (2001) Chapter Ocean Surface Water Mass Transformation. International Geophysics Series, 77, 317-336. https://doi.org/10.1016/S0074-6142(01)80126-1

[22] Fairbanks, R. (1989) A 17,000-Year Glacio-Eustatic Sea Level Record: Influence of Glacial Melting Rates on the Younger Dryas Event and Deep Ocean Circulation. Nature, 342, 637-642. https://doi.org/10.1038/342637a0 
[23] Vellinga, M. and Wood, R.A. (2002) Global Climatic Impacts of a Collapse of the Atlantic Thermohaline Circulation. Climate Change, 54, 251-267. https://doi.org/10.1023/A:1016168827653

[24] Zuo, H., Balmaseda, M.A. and Mogensen, K. (2017) The New Eddy-Permitting ORAP5 Ocean Reanalysis: Description, Evaluation and Uncertainties in Climate Signals. Climate Dynamics, 49, 791-811. https://doi.org/10.1007/s00382-015-2675-1

[25] Hersbach, H., Bell, B., Berrisford, P., Hirahara, S., Horányi, A., Muñoz-Sabater, J., et al. (2020) The ERA5 Global Reanalysis. Quarterly Journal of the Royal Meteorological Society, 146, 1999-2049. https://doi.org/10.1002/qj.3803

[26] Madec, G. (2008) NEMO Ocean Engine. Note du Pôle de modélisation, No 27, Institut Pierre-Simon Laplace (IPSL), France.

[27] Large, W.G. and Pond, S. (1981) Open Ocean Momentum Flux Measurements in Moderate to Strong Winds. Journal of Physical Oceanography, 11, 324-336. https://doi.org/10.1175/1520-0485(1981)011<0324:OOMFMI>2.0.CO;2

[28] Obukhov, A.M. (1946) Turbulence in an Atmosphere with a Non-Uniform Temperature. Boundary-Layer Meteorology, 2, 7-29.

https://doi.org/10.1007/BF00718085 